\title{
AutoAVAliAÇÃo INSTITUCIONAL: A PERCEPÇÃO DOS PAIS SOBRE O TRABALHO DA ESCOLA
}

\author{
Institutional self-evaluation: parents' perception of the school work
}

\begin{abstract}
RESUMo Este artigo discute dados de uma pesquisa que buscou identificar percepções dos pais sobre o que uma escola precisa ter para ser considerada de boa qualidade. Trata-se de recorte de uma pesquisa mais ampla que investigou a possibilidade de uma escola da rede pública construir indicadores de qualidade que dialoguem com os indicadores externos. Como procedimento metodológico, optou-se pela abordagem qualitativa de cunho fenomenológico, que contemplou estudos teóricos de natureza bibliográfica e documental e trabalho de campo feito por meio da proposição de dois questionários aos pais/responsáveis de uma escola da rede pública municipal de São Paulo. Os dados revelam que, na percepção dos pais, uma escola de boa qualidade possui os seguintes traços: realiza o trabalho em equipe, usa tecnologias no processo educacional, alfabetiza as crianças na idade certa, tem acompanhamento do trabalho realizado, envolve os alunos em projetos, busca solução para os conflitos escolares, entre outros.
\end{abstract}

Palavras-chave: AvaliaçÃo InStitucional. Conflitos EscolaRES. QUALIDADE DE ENSINO. PAIS DE Alunos.

ABSTRACt This article discusses data from a survey that sought to identify parent's perceptions of what a school must have to be considered of good quality. It is a cut of a broader research that investigated the possibility of a school in the public network constructing quality indicators that dialogue with external indicators. As a methodological procedure we opted for the qualitative approach of a phenomenological perspective that included theoretical studies of bibliographical and documentary nature and fieldwork carried out through the proposition of two questionnaires to the parents / guardians of a school in the municipal public network of São Paulo. The data show that, in the parent's perception, a good quality school has the following traits: it performs teamwork, uses technology in the educational process, literacy children at the right age, accompanies the work done, involves students in projects, Search for solutions to school conflicts, among others.

KEY-WORDS: INSTITUTIONAL EVAlUATION. SCHOOl CONFLICTS. TEACHING QUALITY. PARENTS OF STUDENTS.

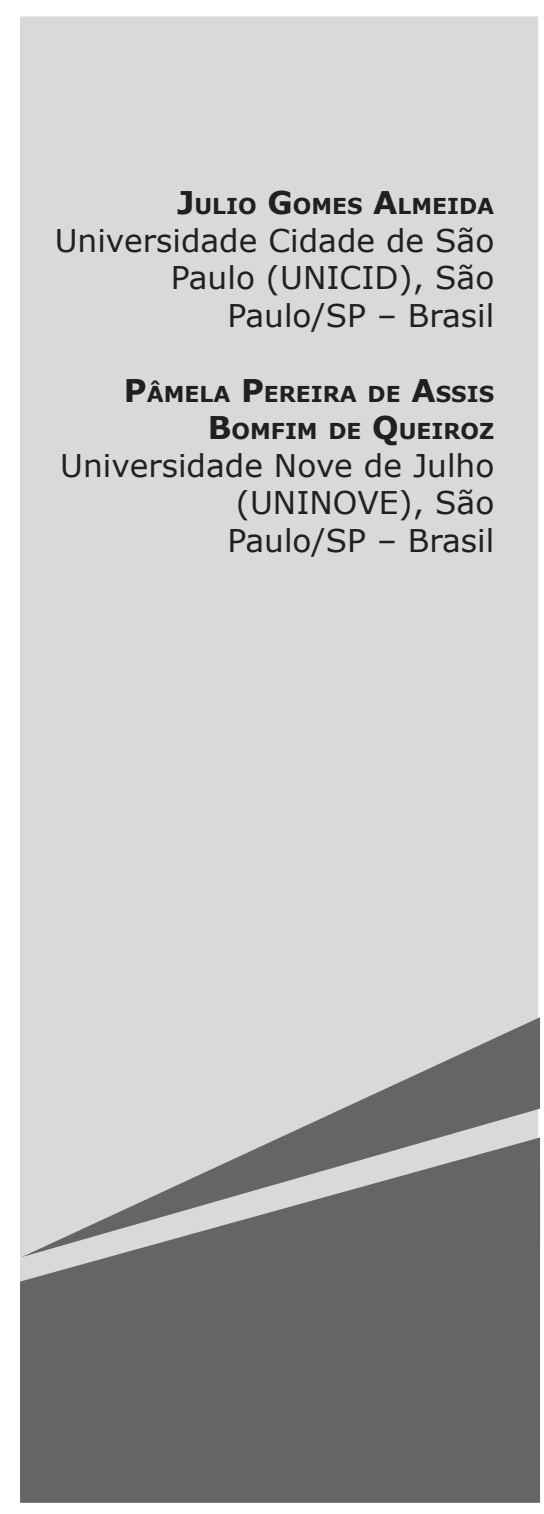




\section{INTRODUÇÃO}

C om direito à educação assegurado pela Constituição de 1988 e emenda 14, de 1996, a garantia de padrão de qualidade passa a ser o grande desafio para a sociedade brasileira. Emerge então a necessidade de busca desse padrão de qualidade, bem como, de construção de instrumentos com certo grau de credibilidade científica para medi-la. A cobrança de definição desse padrão e da construção desses instrumentos vem tanto de setores sociais internos quanto de forças externas. Estes, via de regra, preocupados com a formação de mão de obra capacitada para operacionalizar seus investimentos no país e aqueles preocupados com a formação da juventude para continuar estudos, ingressar no mundo do trabalho e exercer a cidadania.

Nesse cenário, o governo brasileiro vem se empenhando e organizando políticas e ações voltadas para a definição desse padrão de qualidade e tentando criar instrumentos que possam medi-lo. Um exemplo desse empenho é a criação do Sistema de Avaliação da Educação Básica (SAEB), em 1997. A partir de 2007, passa a fazer parte desse sistema o Índice de Desenvolvimento da Educação Básica (IDEB), construído por meio de dois indicadores: os resultados obtidos pelos alunos nas avaliações externas, no caso da escola onde se desenvolveu a pesquisa a Prova Brasil, e o fluxo escolar.

A criação de um sistema centrado na aceitação dos resultados obtidos pelos alunos nas avaliações externas como medida de qualidade do ensino coloca em foco, no Brasil, a polêmica sobre a suficiência dessas avaliações como medida de qualidade da educação. Nesta discussão, alguns conceitos ganham destaque, entre eles vale destacar as questões da regulação do trabalho escolar, da responsabilização do professor pelo fracasso dos alunos, da participação das famílias na gestão da escola, da bonificação por resultados, entre outras.

Embora o desempenho dos alunos nos exames padronizados seja um indicador da qualidade do ensino, cabe o questionamento a respeito da sua suficiência para avaliar todo trabalho da escola. Faz-se necessário considerar não apenas esses resultados, mas também as condições em que são produzidos. Bauer (2012) destaca a importância de se

\begin{abstract}
...agregar às avaliações de desempenho do aluno outros instrumentos capazes de diagnosticar a influência do trabalho docente nos resultados obtidos, assim como detectar com mais precisão outros fatores que podem ser associados à melhoria desses resultados (BAUER, 2012, p. 76).
\end{abstract}

Em concordância com Bauer (2012), um grupo de educadores da unidade buscou parceria junto a uma universidade da região e, mediante essa parceria foi possível elaborar e desenvolver o projeto "Autoavaliação institucional: a construção de indicadores que possibilitem o diálogo com as avaliações externas", que teve como objetivo investigar as possibilidades de uma escola pública construir indicadores próprios de qualidade podendo assim dialogar com os indicadores do sistema com vistas à definição de um padrão de qualidade negociada.

Participaram da pesquisa gestores, professores, funcionários e alunos da unidade. Neste artigo, apresentamos uma discussão dos dados produzidos junto aos responsáveis/pais de alunos.

\section{AVALIAÇÕES EXTERNAS: QUESTÕES CON- CEITUAIS}

A educação constitui-se em campo de múltiplos interesses em disputa e a definição de um padrão de qualidade precisa ser resultado de negociação. Freitas (2005) discute a natureza da qualidade, que se pretende como forma de enfrentamento da noção de qualidade adotada pelas políticas neoliberais fundadas em uma pseudoparticipação que visam legitimar padrões de qualidade externos à escola. Nesse sentido, esse autor considera que um padrão de qualidade adequado para a escola pública precisa ser resultado de um 
processo que envolve diferentes aspectos. Discutindo a noção de qualidade negociada, ele destaca que tal noção contrasta com a versão dominante nas políticas neoliberais, como vemos a seguir:

Ao destacarmos o seu caráter negociável isso não significa deixar de lado outros aspectos da natureza da qualidade. Significa apenas a escoIha de um aspecto em que esta definição contrasta mais abertamente com a noção corrente de qualidade adotada pelas políticas públicas neoliberais cuja concepção é quase sempre eivada de uma pseudoparticipação que objetiva legitimar a imposição verticalizada de "padrões de qualidade" externos ao grupo avaliado (FREITAS, 2005, p. 121).

A noção de qualidade negociada evita a legitimação de padrões de qualidade definidos fora da escola por meio de processos sustentados em uma pseudoparticipação. Assim, na perspectiva de Freitas (2005), o padrão de qualidade precisa estar apoiado em uma construção local, como se pode entender da citação seguinte:

A ideia de que mudança é um processo está fortemente presente no conceito de "qualidade negociada”. A mudança é uma construção local apoiada e não uma transferência desde um órgão central para a ponta do sistema. Tal construção é guiada por um projeto pedagógico da instituição local - consideradas as políticas globais emanadas dos órgãos centrais - que configura uma cesta de indicadores com os quais se compromete e se responsabiliza demandando do Poder Público as condições necessárias a sua realização (FREITAS, 2005, p. 121).

A partir dessa noção de qualidade, é possível responsabilizar e comprometer os educadores e também o poder público que fica obrigado a garantir as condições para a realização do trabalho. Dessa forma, assumimos como foco central da pesquisa a ideia de que é possível uma escola pública participar da definição de um padrão de qualidade do seu trabalho, construindo indicadores internos a partir da mobilização da comunidade escolar e assim dialogar com os indicadores externos.

Com relação à regulação do trabalho escolar, Freitas (2005) assinala que, embora ela seja vocação de toda política pública, tem assumido um sentido de mudança na ação do estado que deixa de intervir no mercado, exceto na condição de avaliador, como vemos no trecho seguinte:

Regular em sentido amplo do termo é vocação de toda política pública, entretanto "regulação" foi um termo construído no interior das "políticas públicas neoliberais", cuja eficácia maior no Brasil foi obtida na gestão de Fernando Henrique Cardoso, para denotar uma mudança na própria ação do Estado, o qual não deveria intervir no mercado, a não ser como um "Estado avaliador" (cf. DIAS SOBRINHO, 2002b). As políticas regulatórias querem, em áreas estratégicas, transferir o poder de regulação do Estado para o mercado, como parte do processo amplo marcado por várias formas de produzir a privatização do público (FREITAS, 2005, p. 913).

As políticas regulatórias que, segundo Freitas (2005), se voltam para transferir o poder de regulação do Estado para o mercado, trazem consigo a ideia de que a escola tem que prestar contas dos investimentos que nela são feitos e, por meio desse processo, acabam impondo aos educadores a responsabilização pelas deficiências do sistema escolar, como também assinala Afonso (2005): 
De facto, a imputação de responsabilidades aos professores tem sido, em diferentes propostas de reforma, a estratégia mais frequente para justificar o que se considera ser a má situação do ensino e das escolas. A discordância que mantemos a este e outros traços exemplificativos da prática discursiva neoconservadora não nos impede, porém, de procurar um aprofundamento teórico que contribua para o debate em torno da legitimidade para se estabelecer em modelos de responsabilização profissional dos professores. Esta responsabilização profissional, no entanto, deve ser vista em confronto com outras formas de responsabilização e discutida face ao exercício (legítimo) do controlo por parte do Estado, e/ou de outros sectores e actores sociais, sobre o que ensina e como se ensina nas escolas publicas ou de interesse público (AFONSO, 2005, p. 42).

Como Freitas (2005), também Afonso (2005) considera exercício legítimo o controle do Estado ou de outros setores sociais sobre o que se ensina na escola pública, inclusive para "fazer cumprir direitos arduamente conquistados nas lutas sociais, entre eles o direito de acesso ao conhecimento historicamente acumulado por meio de processos escolares" (FREITAS, 2005, p. 912). O que se critica é regulação como forma de responsabilização apenas dos professores pelas dificuldades dos sistemas ou como modo de transferir o controle do Estado para a iniciativa privada.

Uma das maneiras de implantar políticas de responsabilização que vêm sendo largamente utilizadas por gestores dos sistemas educacionais é a bonificação por resultados, outro conceito que se destaca na polêmica hoje presente nas discussões sobre avaliação. Alavarse, Machado e Bravo (2013) apontam que os processos de responsabilização fun- damentados na distribuição de bônus podem induzir um conjunto de respostas de cunho utilitarista em algumas "escolas ou redes de ensino, visando garantir-lhes melhores posições em rankings decorrentes da divulgação dos resultados obtidos" (ALAVARSE; MACHADO; BRAVO, 2013, p. 26).

Discutindo os efeitos dessa política na dinâmica da escola, Alavarse (2012) considera inadequada a política de distribuição de bônus uma vez que, entre outros efeitos, pode provocar divisão entre os professores, o que dificulta a luta, a conquista e a consolidação dos direitos dos trabalhadores da educação. Na citação, a seguir, o autor mostra que os efeitos dessa política têm outras consequências para o trabalho escolar.

Uma razão é de princípio político. Essas políticas estabelecem uma divisão entre os profissionais da educação e essa divisão não ajuda na luta que os trabalhadores da educação desenvolvem, há muitos anos, pelo atendimento de seus direitos. É como se você individualizasse, em algum grau pelo menos, as tentativas de melhoria salarial, por exemplo. A segunda razão decorre do próprio processo de mensuração de resultados a partir dos quais serão calculados os bônus. Essas avaliações, como já salientei, não captam todo o trabalho da escola. Ademais, todos os resultados estão sujeitos a erros de medida - inerentes a todo processo de medida que, frequentemente, são ignorados na divulgação dos mesmos. Então, como se poderia avaliar o trabalho dos profissionais da educação, inclusive a ponto de bonificá-los, se se parte de um instrumento que não capta tudo o que eles fazem e ainda introduz imprecisões? No mínimo isso é injusto e incompleto (ALAVARSE, 2012, p. 127). 
Autores reconhecidos na área mostram que a aceitação das avaliações em larga escala como medida de qualidade é uma política cujos desdobramentos precisam ser problematizados. Dessa forma, educadores da escola, onde se desenvolveu a pesquisa, decidiram investigar a possibilidade de construção de indicadores de qualidade da própria escola e que, por isso, considerassem as especificidades do trabalho que ali se desenvolvia, sem, contudo, desconsiderar os resultados das avaliações externas, que são também indicadores importantes.

Assim, a qualidade não seria medida tomando como referência um padrão definido de forma unilateral e distante de onde o trabalho educacional efetivamente acontece, mas negociado com aqueles atores que estão na escola na condição de prestadores de serviços educacionais ou de usuários desses serviços. Discutir e aprofundar os conhecimentos a respeito de avaliação educacional, com o objetivo de criar indicadores de qualidade que dialoguem com os indicadores do sistema, considerando as necessidades do território no qual a escola está inserida, pode constituir-se em caminho profícuo na construção de um padrão de qualidade, se não aceito por todos que, pelo menos goze de certa credibilidade. Nessa perspectiva, foi elaborado e desenvolvido o projeto, do qual apresentamos neste artigo um recorte.

\section{Metodologia dA PESQUisA}

Em sua formulação inicial, a pesquisa previu como procedimento metodológico a abordagem qualitativa de cunho fenomenológico que contemplasse estudos teóricos de natureza bibliográfica e documental, e pesquisa de campo realizada por meio de observação participante e aplicação de questionários com questões abertas aos diferentes segmentos que compõem a comunidade escolar. $\mathrm{O}$ desenvolvimento da pesquisa foi organizado em duas fases distintas e complementares.

O foco da primeira fase foi a formação dos pesquisadores, necessária ao desenvolvimento da pesquisa, realizada por meio de reuniões semanais na escola envolvendo os participantes do grupo de pesquisa, com participação quinzenal do pesquisador responsável. Além desses procedimentos, foram feitos seminários para o grupo, organizados pelos próprios participantes e discussões nos espaços de trabalho coletivo da escola com vistas a ampliar as discussões feitas no grupo para o conjunto de educadores da unidade. Assim, essas reuniões constituíram-se em importantes espaços de autoformação do grupo com repercussão importante na escola como um todo.

Nessa fase, como previsto inicialmente, o grupo construiu um questionário composto por seis questões abertas versando sobre a noção de avaliação escolar e sua finalidade, o qual foi proposto a todos os segmentos da comunidade escolar. Para a realização dessa atividade, os professores pesquisadores dividiram-se em grupos e cada grupo ficou responsável pela coleta de dados junto a um segmento. No nosso caso, ficamos responsáveis por essa tarefa junto aos responsáveis/pais de alunos. Os dados coletados foram apresentados no grupo para a sistematização e análise coletiva. Foram convidados para participar dessa fase da pesquisa os pais/responsáveis de uma turma do último ano do Ciclo I e de uma turma do último ano do Ciclo II do ensino fundamental - escolhidas por sorteio - tendo comparecido 20 pais/responsáveis: 12 da primeira turma e oito da segunda.

Além da formação como pesquisador, essa fase da pesquisa ajudou também na formação profissional, uma vez que foi possível utilizar a teoria para compreender o significado de algumas práticas desenvolvidas dentro da escola e também perceber que a reflexão sobre algumas práticas serviu para compreender melhor alguns conceitos teóricos.

\section{A NOÇÃo dE AVALIAÇÃo}

No que se refere à noção de avaliação educacional, a maior parte dos pais pesquisados acredita que é uma forma de verificar se o aluno conseguiu apreender o conteúdo ensinado pelo professor e se tem comportamento adequado na sala de aula. Os dados permi- 
tem inferir que pelo entendimento dos pais na escola se aprende não só os conteúdos escolares mas também os comportamentos exigidos na vida social. Dessa forma, percebe-se entre os pais uma tendência que vê a avaliação como meio de verificar a internalização de conteúdos transmitidos e de ajustamento de conduta.

No entanto, é possível notar também que muitos pais começam a ter um olhar diferenciado para a avaliação, percebendo que ela não serve apenas para verificar o conteúdo apreendido, mas também, como aponta uma das respostas do segmento "para saber se os professores estão ensinando bem, se o que ensinam, de fato, é importante e se os funcionários estão realizando de maneira satisfatória suas tarefas".

Nesse contexto, pode-se também identificar uma tendência no sentido de entender a avaliação como forma de regulação do trabalho dos profissionais que atuam na escola Freitas (2005), que pode ser lida como repercussão da ideologia responsabilização que, segundo Afonso (2005), orienta a prática discursiva neoconservadora entre as quais se encontra a imposição dos resultados obtidos pelos alunos nas avaliações externas como indicador de qualidade.

Todavia, não é apenas a ideologia dominante que repercute nas percepções dos pais. Em outras respostas, eles também percebem a avaliação como forma de indução de valores como solidariedade, participação, respeito aos outros, formação política e ética, o que nos leva a crer que também os valores relacionados à cidadania têm repercutido na comunidade escolar.

\section{FINALIDADE DA AVALIAÇÃo}

Com relação à finalidade da avaliação, os pais percebem que essas são utilizadas com a finalidade de verificar, refletir, analisar se os alunos estão aprendendo, se a escola tem uma boa estrutura, se está fazendo um bom trabalho. Alguns pais responderam que a avaliação serve para descobrir e ajudar os alunos que têm mais dificuldades. Como eles consideram que todos os segmentos são avaliados, também afirmam que a avaliação serve para saber o grau de relacionamento entre todos que pertencem ao estabelecimento, o quanto aprenderam, ensinaram, ajudaram, cresceram social e intelectualmente. Novamente, tem-se a ideia de que a escola não ensina somente conteúdos de diferentes disciplinas, mas exerce uma grande influência na formação para a convivência social e ingresso no mundo do trabalho. Diante de tais considerações, é possível perceber que os pais, ao contrário do que se possa pensar, estão atentos ao papel que a escola deve desempenhar e que aquilo que eles apontam como finalidade da avaliação não pode ser alcançado pelas avaliações padronizadas. São necessários procedimentos avaliativos que envolvam outras dimensões além dos resultados obtidos nas avaliações externas.

$\mathrm{Na}$ segunda fase da pesquisa, o foco foi o desenvolvimento de um processo de mobilização da comunidade escolar para a discussão da avaliação na escola com vistas à construção de indicadores de qualidade que dialogassem com as avaliações externas. $O$ pressuposto, que norteou essa fase da pesquisa, foi o entendimento de que a escola tem condições de mobilizar a sua comunidade em torno de questões importantes e estabelecer um processo coletivo de identificação de aspectos a serem avaliados e também dos critérios para avaliá-los. Essa mobilização, essencial para que as decisões tomadas sejam respeitadas por todos, se deu na escola pesquisada a partir da questão: o que uma escola precisa ter para ser considerada boa?

O ponto de partida dessa discussão foi a realização do "I Seminário sobre Avaliação Institucional: a construção de indicadores que possibilitem o diálogo com as avaliações externas" realizado na escola e que contou com a participação de especialistas da área e aberto à comunidade escolar e às escolas do entorno. A partir do seminário, a discussão dessa questão foi encaminhada pelos professores pesquisadores junto a cada segmento conforme a especificidade de cada um deles. 
No caso dos pais, a discussão foi incluída como na pauta de uma reunião prevista no calendário escolar, quando foram explicados com detalhes os motivos da pesquisa e informados aos pais que, embora importante, a participação naquela parte da reunião não era obrigatória. A questão foi discutida pelos pais que consentiram em colaborar com a pesquisa. As manifestações dos pais sobre "o que uma escola precisa ter para ser considerada boa" foram registradas e posteriormente levadas para o grupo, onde foram categorizadas com as manifestações dos demais segmentos. A partir dessa categorização, foram identificadas seis dimensões do trabalho escolar para serem avaliadas por todos os segmentos: ambiente educativo, prática pedagógica, avaliação do rendimento escolar, gestão democrática e participação da comunidade, autonomia profissional dos educadores e cidadania ativa na escola.

De posse desses dados, foi elaborada a primeira versão do questionário incluindo as seis dimensões e os indicadores correspondentes. Essa versão inicial foi apresentada e discutida com professores e funcionários que participavam do horário de trabalho coletivo da escola, o que possibilitou a criação de uma versão final do questionário discutida com um grupo mais amplo de professores e funcionários do que aquele envolvido na pesquisa. Após a discussão nesse grupo, foi então elaborada a versão apresentada à comunidade escola e também organizado o "I Fórum de Debates sobre a Rede de Proteção Social" aberto a toda a comunidade escolar e que envolveu especialistas e representantes das instituições que compõem essa rede na região. Nesse seminário, foi distribuído o questionário aos pais com orientação sobre o preenchimento e a recomendação de que aqueles que aceitassem participar da pesquisa o devolvessem preenchidos. Devolveram o questionário preenchido 84 pais/responsáveis que constituíram o universo da pesquisa nesse segmento.

\section{AUTOAVALIAÇÃO INSTITUCIONAL: ESCOLA DE QUALIDADE NA PERCEPÇÃO DOS PAIS}

Com o direito de acesso e permanência na escola, legalmente assegurados, a garantia de padrão de qualidade do ensino torna-se nova etapa na luta pela garantia do direito à educação. Essa situação tem gerado um debate que extrapola o campo educacional e atinge diferentes campos da vida social como a política e a economia, com repercussões importantes na organização dos sistemas educacionais. Esse debate - como atesta a vasta literatura produzida sobre o tema nas últimas décadas - tem se dado em torno de indicadores produzidos a partir de resultados obtidos pelos estudantes nas avaliações externas, restando pouco espaço para a inclusão de indicadores que contemplem outras dimensões importantes na definição de um padrão de qualidade para o ensino público.

O exame da literatura permite constatar que, além de ser pouco consideradas outras dimensões além desses resultados, o universo de sujeitos que participam com mais intensidade desse debate também é restrito e merece ser ampliado. A partir dessa constatação, o grupo optou pelo desenvolvimento de uma pesquisa sobre avaliação institucional que permitisse discutir a inclusão de outros sujeitos nas discussões sobre a construção de um padrão de qualidade para a escola pública. A hipótese norteadora da pesquisa foi de que é possível uma escola pública construir indicadores de avaliação que permitam o diálogo com os indicadores externos. Conforme já anunciado, foi então construído um instrumento de coleta de dados proposto a todos os segmentos que compõem a comunidade escolar, cujos resultados obtidos junto ao segmento pais/responsáveis são apresentados e discutidos a seguir.

\section{AMBIENTE EDUCATIVO}

$\mathrm{Na}$ análise dessa dimensão, constituída por seis indicadores: trabalho da equipe em conjunto, orientações coerentes da equipe, 
regras de convivência claras, avaliação periódica das regras de convivência, parâmetros dos educadores da unidade, disciplina na escola e escola como ambiente de aprendizagem e convivência, os pais, em grande maioria, indicam como itens fundamentais na avaliação da escola o trabalho da equipe em conjunto e a disciplina na escola.

Os dois indicadores foram os preferidos também nos demais segmentos, o que é bastante coerente com os discursos que se ouve no cotidiano da escola: falta de coerência e mesmo contradições nas ações da equipe e indisciplina dos alunos como fatores que dificultam o trabalho. Contudo, na análise deste item verifica-se que os pais, diferentes de outros segmentos, apontam como relevante também o indicador permanência dos educadores na unidade. Nesse caso, manifesta-se uma divergência com relação aos segmentos de professores e funcionários que veem a remoção e as possibilidades de afastamentos para outros cargos e funções como direitos consagrados, enquanto os pais enxergam esses expedientes como mecanismos que retiram profissionais da escola e da sala de aula, portanto, que trazem prejuízos para os seus filhos. No trecho seguinte, apresentamos uma análise dessa dimensão a partir das respostas dos professores, como forma de ilustrar essa tensão:

Outro ponto a ser destacado nesta dimensão se refere à baixa quantidade de indicações do item permanência dos educadores na escola. Essa situação contraria os discursos correntes segundo os quais para que se pense e execute um projeto pedagógico consistente é preciso que se conte com uma equipe estável $\mathrm{O}$ baixo percentual de indicações neste item parece colocar em evidência uma tendência corporativista presente na escola. Apontar a necessidade de permanência na escola poderia ser entendido como um questionamento à remoção que se constitui em possibilidade anual de mudança de escola (ALMEIDA; NHOQUE, 2014, p. 5).

A rotatividade de profissionais é de fato um dos grandes problemas da rede municipal de ensino e ela é provocada por diversos fatores, entre eles os afastamentos da sala de aula ou da gestão para ocupar outros cargos, licenças médicas ou a remoção que pode acontecer uma vez por ano. Incluir como indicador a permanência dos educadores na unidade evidencia certa tensão entre interesses dos trabalhadores e usuários dos serviços da escola.

\section{AS PRÁTICAS PEDAGÓGICAS}

A dimensão práticas pedagógicas teve como indicadores de avaliação: uso de tecnologias em sala de aula, conteúdos adequados à realidade, trabalho interdisciplinar, planejamento das aulas, criação de expectativas positivas, recuperação paralela eficaz, espaço para manifestação das dúvidas, respeito ao direito de aprendizagem e uso das avaliações no planejamento escolar. Na avaliação dessa dimensão, a opinião dos pais ficou dispersa entre diferentes indicadores, porém os mais indicados foram uso de tecnologias em sala de aula (48\%) e planejamento das aulas (35\%), uma indicação de que este segmento da comunidade está incomodado com a maneira como as aulas são organizadas e sensibilizadas para a necessidade de uso de tecnologias no processo educacional, entretanto, a dimensão práticas pedagógicas não parece o foco de grandes preocupações dos pais.

\section{AVALIAÇÃo do RENDIMENTO ESCOLAR}

Para avaliar essa dimensão, foram elencados os seguintes indicadores: avaliações internas, avaliações externas, alfabetização na idade certa, ingresso dos alunos em boas escolas, conhecimento dos instrumentos de avaliação, instrumentos internos de avaliação padronizados. Com relação à avaliação dessa dimensão, o indicador mais sugerido pelos pais foi alfabetização na idade certa, com $71 \%$ das indicações. Esse indicador foi fortemente 
indicado por todos os segmentos sugerindo que a alfabetização é um problema para toda comunidade escolar. O segundo indicador mais sugerido pelos pais foi avaliações internas (62\%). Essa preferência pode ser melhor entendida se considerarmos o discurso corrente na comunidade escolar segundo o qual "na promoção automática os alunos não são avaliados pelos professores".

\section{GESTÃo DEMOCRÁTICA E PARTICIPAÇÃO DA COMUNIDADE}

A avaliação dessa dimensão foi constituída pelos indicadores: incentivo e apoio às iniciativas, critérios claros para a divisão das tarefas, gestão ponderada das situações de conflitos, acompanhamento do trabalho escolar, articulação da escola com a rede de proteção integral e participação das famílias na escola. Para avaliar essa dimensão, os indicadores mais sugeridos foram: acompanhamento do trabalho escolar (69\%) e participação das famílias na escola (68\%). Os dois indicadores foram fortemente sugeridos também por outros segmentos como professores e funcionários. Olhando tais dados de forma objetiva, se poderia identificar forte convergência entre os diversos segmentos. No entanto, essa convergência pode ser questionada quando atentamos para o seguinte:

De fato a necessidade de participação da família está muito presente nos discursos da escola, sobretudo dos professores e funcionários e também nos discursos sobre a escola, quer nos oficiais quer nos da academia. No entanto parece importante entender o que se pretende dizer quando se fala em participação da família na escola. Nos discursos da escola a solicitação da presença dos pais tende a relacionar-se com a ideia de que os pais devem ajudar a tomar conta dos filhos, sobretudo daqueles que não apresentam comportamento adequado ou que não estão tendo o desempenho desejado. Já nos discursos sobre a escola é possível destacar duas tendências: uma no sentido da presença da comunidade na escola como forma de controle do trabalho escolar e outra no sentido de entender essa presença como uma possibilidade de formação política da própria comunidade. A reflexão sobre os dados da pesquisa faz entender que a ideia de controle do trabalho escolar pela comunidade tem se configurado na escola como um campo de tensão (ALMEIDA; NHOQUE, 2014, p. 7).

Nessa perspectiva, a presença da comunidade na escola pode ter significado diferente para educadores e gestores das unidades e sistemas de ensino. O mesmo pode se dizer do acompanhamento do trabalho escolar, como vemos a seguir:

Com relação ao acompanhamento do trabalho escolar, nota-se que este é um grande desafio da escola. Como realizar o acompanhamento do que acontece na sala de aula, dos projetos e ações definidos no projeto pedagógico, da aprendizagem dos alunos, dos encaminhamentos realizados pelos professores e pela própria escola? Muitas vezes a própria estrutura dos tempos e espaços da escola são organizados de forma a atrapalhar este acompanhamento. Um exemplo disto é a forma como os resultados das avaliações externas chegam a escola: frequentemente com dois anos de atraso e em linguagem inacessível às pessoas comuns (ALMEIDA; NHOQUE, 2014, p. 7-8).

As citações evidenciam algumas fragilidades do sistema público de ensino, embora os princípios da autonomia da escola e da gestão democrática estejam consagrados na 
Constituição Federal de 1988, na Lei 9.394/96 - Lei de Diretrizes e Bases da Educação Nacional e legislações delas decorrentes. O trabaIho escolar e a formação continuada dos professores, em grande medida, são gerenciados de fora da escola por meio de programas, decretos e portarias elaborados sem participação dos pais, dos alunos e dos educadores que estão na escola. O mesmo tem acontecido com a participação da família na escola. Definiu-se legalmente que a família deve participar, comunicaram à família e à escola, mas esqueceram de estabelecer com elas os caminhos dessa participação.

\section{AUTONOMIA PROFISSIONAL DOS EDUCA- DORES}

Essa dimensão foi composta pelos indicadores: motivação para o trabalho, alternativas pedagógicas para as aulas, busca de soluções para os problemas, discussão coletiva das situações cotidianas, busca da atualização e formação profissional. Na análise dessa dimensão, a maior parte das indicações dos pais recaiu nos indicadores motivação para o trabalho (62\%) e busca de solução para os problemas (71\%).

No caso do primeiro indicador, a escolha dos pais parece convergir com os discursos correntes: os professores encontram-se desmotivados. A inclusão desse indicador como critério de avaliação coloca como desafio para os formadores e gestores de políticas públicas de educação a motivação desses profissionais.

No que se refere à busca de solução para os problemas, os pais tocam também um ponto fundamental no processo educacional: a transferência para as famílias da solução de conflitos nos quais seus filhos se envolvem na escola. Aqui parece emergir outro ponto de tensão entre a escola e a família. De um lado, a escola que considera dever dos pais educar os filhos para não promoverem nem se envolverem em confusão e, de outro, as famílias que ficam impotentes diante de situações em que a palavra da escola parece ter menos consistência que a palavra das crianças.

\section{CIDADANIA ATIVA NA ESCOLA}

A análise dessa dimensão foi pautada pelos seguintes indicadores: ações da escola no território, elaboração e desenvolvimento de projetos, participação dos alunos em projetos, busca de conhecimento, além do oferecido pela escola, conhecimento e defesa dos próprios direitos, participação nas atividades escolares. Para a análise dessa dimensão, os pais sugerem como indicadores preferenciais a participação dos alunos nos projetos (64\%) e busca de conhecimento, além do oferecido pela escola (60\%).

A escolha do primeiro indicador converge com os discursos políticos e acadêmicos e sociais de que a participação em projetos tem grande importância na formação. A comunidade também parece entender essa importância. Com relação ao segundo indicador, é possível fazer duas inferências: sensibilização da comunidade no sentido de que a escola não é o único lugar de sistematização e transmissão de conhecimento e também o questionamento sobre a sua eficácia na atualidade. Buscar conhecimento, além do oferecido pela escola, pode significar também o reconhecimento de que o ensino oferecido é precário.

\section{CONSIDERAÇÕES FINAIS}

No que se refere à percepção dos pais a respeito do que uma escola precisa ter para ser considerada de qualidade, a pesquisa revela que esse segmento está bem atento ao que acontece na escola e que, quando incluído na discussão, manifesta com clareza sua opinião sobre o papel que a escola exerce e o papel que ela deve exercer. Nesse sentido, suas percepções acerca do que vem a ser uma escola de qualidade pode constituir em valiosa contribuição.

A pesquisa revela que esse segmento percebe como negativas as repercussões de situações como falta de planejamento das aulas, rotatividades de profissionais, falta de articulação da equipe escolar, entre outras. Por sua vez, aparecem como positivas nas manifestações desse segmento o trabalho colaborativo da equipe, o uso de tecnologias em sala 
de aula, o envolvimento dos alunos em projetos, a participação das famílias nas tomadas de decisões, o acompanhamento do trabalho escolar, entre outros.

Com relação à existência de parâmetros de avaliação da qualidade do ensino oferecido, a pesquisa revela que este constitui um desafio para a escola. Não se pode dizer, a partir dos dados da pesquisa, que haja consenso na comunidade escolar sobre o que seria ensino de qualidade e como essa qualidade poderia ser alcançada. Considerando-se que avaliação supõe juízo de valor, sempre ancorado em concepções e interesses diferenciados e em grande medida antagônicos, não se poderia esperar tal consenso.

Entretanto, resta como desafio possível a mobilização da comunidade escolar com vistas à construção de um sistema próprio de avaliação no qual se defina um padrão de qualidade com envolvimento da comunidade escolar, a partir das questões locais sem, contudo, desconsiderar que a unidade escolar encontra-se vinculada a um sistema que precisa garantir conquistas sociais historicamente construídas, isto é, um padrão de qualidade negociado.

\section{REFERÊNCIAS}

AFONSO, A. J. Avaliação educacional: regulação e emancipação: para uma sociologia das políticas avaliativas contemporâneas, 3. ed. São Paulo: Cortez, 2005.

ALAVARSE, Ocimar Munhoz. Entrevista por Almeida J. G. M. Revista@mbienteeducação, jan./ jun., 2012. Disponível em: <http://www.cidadesp. edu.br/old/revista_educacao/pdf/volume_5_1/ educacao_01_126-131.pdf>. Acesso em 25 jul. 2015.

ALAVARSE, O. M.; MACHADO, C.; BRAVO, M. H. Avaliações externas e qualidade na educação Básica: articulações e tendências. Est. Aval. Educ. São Paulo, v. 24, n. 54, p. 12-31, jan./abr. 2013. Disponível em: <http://www.fcc.org.br/pesquisa/ publicacoes/eae/arquivos/1783/1783.pdf>. Acesso em 20 nov. 2014.

ALMEIDA, J. G.; NHOQUE, J. R. Auto avaliação institucional: a mobilização da comunidade na definiçãao de indicadores de qualidade. Anais do III Congresso Nacional de Avaliação em Educação: III CONAVE. Bauru: CECEMCA/UNESP, 2014, p. 1-12.

BAUER, A. É possível relacionar avaliação discente e formação de professores? A experiência de São Paulo. EDUC. Rev. [on-line], 2012, vol. 28, n. 2, p. 61-82. Disponível em <http//www.sielo.br/ pdf/edur/v28n2/a04v28n2.pdf> Acesso em 28 dez. 2014.

FREITAS, Luiz Carlos de, e outros. Avaliação Educacional: Caminhando pela Contramão: 3. ed. Petrópolis: Vozes, 2011.

FREITAS, Luiz Carlos de. Qualidade negociada: avaliação e contra-regulação na escola pública. Educ. Soc. Campinas, vol. 26, n. 92, p. 911-933, Especial, out. 2005. Disponível em <http://www. scielo.br/pdf/es/v26n92/v26n92a10.pdf> Acesso em 14 set. 2015. 


\section{DADOS DOS AUTORES}

\section{JuLIO Gomes ALMEIDA}

Doutor em Educação pela Universidade de São Paulo. Supervisor Escolar da Prefeitura do Município de São Paulo, Professor do Programa de Mestrado da Universidade Cidade de São Paulo, Professor da Faculdade Santa Izildinha.São Paulo/SP - Brasil.gomes_almeida@uol.com.br

\section{PÂMela Pereira De Assis Bomfim de QUeIROZ}

Licenciada em Letras pelo Centro Universitário Fundação Santo André. Graduada em Pedagogia pela Universidade Nove de Julho. Professora de Língua Portuguesa da Educação de Jovens e Adultos na Prefeitura Municipal de Santo André e Professora de Língua Portuguesa do Ensino Fundamental e Médio da Prefeitura Municipal de São Paulo.São Paulo/SP - Brasil.pa_bomfim@ hotmail.com

Submetido em: 24-01-2016

Aceito em: 28-03-2017 